\title{
Barriers towards exercise and physical activity of different ethnic groups in middle-aged female Singaporeans
}

\author{
Estella Qian Lin Bu, Ho Jin Chung* \\ Physical Education and Sports Science, National Institute of Education, Nanyang Technological University, Singapore
}

The government has collaborated with the Health Promotion Board in coming out a bountiful of initiatives for the citizens to engage in exercise. Despite the initiatives, the obesity rate in middle-aged women is still high. This study seeks to understand and identify the vast barriers that prevent middle-aged women from exercising. Purposive sampling and semi-structured interview were conducted for the participants. The analysis of the interview revealed the significance of barriers in three areas: Priority of Family and Work Commitments, Minimal Promotion of
Subsidized Initiatives by the Government, and Discrimination through the Usage of Language. It highlights that racial barriers are minimal and better time management would be appropriate to engage a healthier lifestyle. The study suggested female Singaporeans to incorporate sports in the lifestyle, more aggressive promotion of subsidized initiatives and the use of common languages (English) in the exercise class.

Keywords: Barrier, Physical activity, Ethnic group, Female, Singapore

\section{INTRODUCTION}

As Singapore becomes more affluent, the populations are more inclined to face the issue related to obesity. Obesity is highly correlated with cardiovascular diseases that invariably have consequences of hitting the general population. According to Sport Singapore (2015), with the vision 2030, collaborative efforts among government, health professionals and the community are emphasised. Physical activity and sports can be seen as a useful tool in the development of micro (individual), meso (group), and macro (societal) level. On the micro level, participation in sports results in being healthier and reduces the chances of being obese. The surged in obesity rates in developed countries like those that Singapore can be observed and actions are needed to be taken. Engagement of physical activity also brings about the growth and personal development of an individual in terms of values and morals. Secondly, in terms of meso (group) development, physical activity and sports is able to bring about cohesion in people of dif- ferent race and religions. This is of paramount importance for Singapore due to the nature of being a multiracial country. Much works has been done towards eliminating racism on the terraces but some groups of people still do not go to matches because they felt that the atmosphere is too intimidating (Suter, 2009). With considerations to the continual efforts to reduce racism through physical activity, careful attempts have to be undertaken to achieve improvements. Lastly, on a marco (societal) level, the Vision 2030 was formulated to live better through sports through a series of miles stones by 2030. Vision 2030 promotes "Sports Without Boundaries" that makes sports to be inclusive, with opportunities (Sport Singapore, 2015).

With initiatives in sports being affordable, accessible and appropriate for different ages, it focuses on providing quality of life towards the Singapore citizens. With well laid-out planning of Vision 2030, the increased in facilities built that gained accessibility to sports and sports for everyone, the National Sport Participation Survey detailed the increased in nonparticipant of sports
${ }^{*}$ Corresponding author: Ho Jin Chung (iD https://orcid.org/0000-0002-2517-8732 Physical Education and Sports Science, National Institute of Education, Nanyang Technological University, 1 Nanyang Walk, Singapore

Tel: +65-6790-3776, Fax: +65-6869-9260, E-mail: hojin.chung@nie.edu.sg

Received: August 7, 2018 / Accepted: September 10, 2018
This is an Open Access article distributed under the terms of the Creative Commons Attribution Non-Commercial License (http://creativecommons.org/licenses/by-nc/4.0/) which permits unrestricted non-commercial use, distribution, and reproduction in any medium, provided the original work is properly cited. 
from $45 \%$ (2005) to $54 \%$ (2011). The statistic of middle-aged adults is alarming because in 2011, only 33\% are regular participant of physical activity (Sport Singapore, 2015). The middle-aged women are very sensitive to their body as ageing is prominent after the age of 40 (Moon et al., 2018). Ageing is strongly associated with changes in body composition (Rossi et al., 2017). According to Lee and Oh (2015), when the balance of this body composition is broken, the muscular strength is reduced and causes sarcopenia. The lack of exercise and physical activity may lead to the imbalance of body composition. However, in Singapore, there are many barriers for them to participate in exercise and physical activity. The definition of barriers can be translated to a series of obstacles that prevents the access of exercise to different ethnic groups in middle-aged female Singaporeans (Justine et al., 2013). With such comprehensive aids from the society, the motivation towards partaking in physical activity is still stagnant. In early research, it shows that exercising reduces stress in general (Norris et al., 1992).

However, recent research shows that there is no relation between physical activity and perceived stress (Nguyen-Michel et al., 2006). More recent research identified that self-efficacy and social support are important factors in the determination of physical activity (Blake et al., 2017). Self-motivation to exercise and social support by family members and friends thus determine the chances of partaking in physical activity regularly. In addition, to explain the low number of physical activity participation rate, research has also shown that older women perform less physical activity as compared to younger women (Scharff et al., 1999). Little studies have been done on identifying the barriers towards sports of different ethnic groups in female middle age Singaporeans, thus there have been no evidence to support the result of past phenomenological studies. In this sense, this study identifies the barriers towards physical activities of different ethnic groups in middle-aged Singaporeans and it provides an account of the lived struggled experiences faced by them.

\section{Trends for weight gain}

The advert of technology and modernization of societies has resulted in the dependency of convenience. High reliance of technology creates excessive convenience for people contributing to workplace sedentary behavior (Waters et al., 2016). For example, instead of walking to a colleague's place to convey information, people tend to rely on technologically dependent tools while removing the aspect of moving. Based on a research, estimate of $77 \%$ of the time is spent in sedentary activities (Waters et al.,
2016). Obesity is highly correlated to a sedentary lifestyle and is a growing worldwide epidemic. Obesity is resulted from the excessive accumulation of body fats and is highly associated with major chronic diseases as well as an increase in mortality. With the increased in the quality of life in Singaporeans, eating habits changes coupled with the lack of physical activity resulting in the increased in obesity rate. According to Health Promotion Board (HPB), there is an upward trend on the statistic of obesity (body mass index $[\mathrm{BMI}]>30 \mathrm{~kg} / \mathrm{m}^{2}$ ) among Singaporeans adults from 5.5\% in 1992 and 8.6\% in 2013 (Health Promotion Board, 2016). Moderately, the obesity rate in women is higher than men (Malhotra et al., 2013). Obesity among women is more prevalence than man may due to the nature of housekeeping and child rearing. Modernization encourages women to seek a balance between having a career and managing household. The need to have dual income in the family encourages women to find a career. With such, leisure time does not come easily for working women.

According to the National Sports Participation Survey for 2011, 54\% of the citizens do not exercise and leads a sedentary life. The requirement of a sedentary life is not participating in any form of physical activity or sports in the past 3 months. At a gender level, the survey also recorded that $58 \%$ of Singaporean females leads a sedentary lifestyle. It can also be translated that only 4 out of 10 Singaporean women works out on a regular basis. Another possibility for weight gain can be due to overwhelming psychosocial stress (Ball et al., 2017). The action undertaken for psychosocial stress is usually compulsive eating. Stress also having certain negative physiological effects that contributes to weight gain.

\section{Government initiatives}

In recent years, the government has formulated initiatives to encourage healthy living in Singapore. It includes making physical activities and healthy eating more accessible. The Healthy Living Master Plan is the collaboration of Ministry of Health and HPB and they aim to ensure the affordability, accessibility and the participation of all Singaporeans in physical activity. Another Initiative by Sport Singapore is ActiveSG. This initiative encourages sports for everyone. Gym, Swimming and exercises classes are open up for registrations at an affordable price. The accessibility of the facilities is well distributed and users are able to gain access to these facilities easily. Free ActiveSG membership is only applicable to Singaporeans and permanent resident. Upon registration for the free ActiveSG membership, members are given a free ActiveSG $\$ 100$ which can be used got swimming and gym admis- 
sion or booking of ActiveSG sport facilities (Sport Singapore, 2017). Free credits are given as a form of encouragement to users to take the first step in having a healthy lifestyle.

Health Promotions Board is an initiative set off in sync to the Healthy Living Master Plan. The physical activity programmes such as National Steps Challenge, Lose to Win and Sundays@The Park, are initiated and managed for Singaporeans to stay active (Health Promotion Board, 2017). As one of the physical activity programmes, the National Steps Challenge is a pedometer-based physical activity initiative that taps on technology to take as many steps as possible. Rewards are given when participants are able to obtain certain physical milestone (Health Promotion Board, 2017). The Sundays@The Park programme offers a wide range of exercise classes and across all ages. All of the programmes mentioned are free-of-charge.

\section{Gym memberships in Singapore}

Fitness gyms are highly accessible and have equipment that focuses in agility, strength, power, and flexibility. Gym work enables people to build on bodily factor as well as psychological factors (Stewart et al., 2013). Based on one's physical capabilities, adjustments and variations can be made across all levels. One of the most common physical activities that Singaporean partakes is visiting the gym regularly. In Singapore, gym membership costs from SGD\$80-SGD $\$ 200$ monthly depending on the equipment and location. While the more affordable gym costs SGD $\$ 80$, the location of the gym is limited. With more extensive gym costing over SGD $\$ 100$, second considerations are given due to financial restrictions.

\section{MATERIALS AND METHODS}

\section{Participants}

Adopting the purposeful sampling technique (Green and Thorogood, 2018), data collection was conducted between December 2017 and February 2018. Participants were selected based on the two essential criteria being that the participants have experienced the phenomena being studied and were willing to share their experiences (Holloway and Galvin, 2017). Participants aged between 40 to 55 years old and did not participate in any form physical activity for the past 6 months. Semistructured interviews were directly administered at parks (woodlands) mainly in the northern part of Singapore. Before conducting the interviews, participants were informed on the objectives of the study, confidentiality of their personal details and their rights for withdrawal at any point of the survey. Three respondent of each race (Chinese, Malay,and Indian) participated in the study, representing the each of the ethnic group. Interviews were conducted at the participant's house and the average duration for each interview is $30 \mathrm{~min}$.

\section{Data collection}

Following ethical approval from an Institutional Review Board of a university, the first author liaised with each participant for the interviews. The data was collected from semistructured interviews. Qualitative research methods involve the systematic collection, organization, and interpretation of textual or visual material derived from talk or observation (Malterud, 2001). With semistructured interviews adopted, it enabled a degree of flexibility to provide information and set exploration on sensitive topics which may not be ideal to be discussed in a private setting.

\section{Data analysis}

The analysis of database from HPB has also been used to aid in the discovery of lack of exercise in middle-aged Singaporean women. Interview questions were formulated based on two main areas (Moustakas, 1994) and they were: what they have experienced (textural description) and how they experienced it (structural description). Interviews were transcribed verbatim for each session with the participant. In accordance with Dale (1996), the two authors separately and independently analysed the interview transcripts to increase trustworthiness. The analyses of the data were done through multiple reading, formation of the concepts and lastly the creation of themes. Once the researchers have completed the transcript, a follow-up session was done for member checking to confirm the accuracy of it.

\section{RESULTS}

The result of the analysis revealed three top barriers towards sports of different ethnic groups in middle-aged female Singaporean. Result revealed (a) priority of commitments, (b) minimal publicity of subsidized initiatives, and (c) discrimination through the use of language.

\section{Priority of family and work commitments}

All participants agreed that the engagement of physical activity is time consuming. The priority of managing the household and taking care of their grandchildren or children are the most important.

Interviewee 3: (...) like after work you go home then you need 
to cook for your family then after that, you need to wash the plates. Also need to make sure house is clean. Cause I work, the whole entire day I (am) not at home. So will be dirty then need to wash clothing (...)

Her main concern is that she does not have the luxury of time to engage in any sort of exercise classes that is provided by the community. What is striking Angela is that managing the household is her upmost duty. She priorities household chores and the management of her family and hence achieve a sense of productivity, achievement and satisfaction from the successful managing her household. Similar experience can be found in Interviewee 1 and interviewee 2 through their interviews.

Interviewee 1: (...) I cannot do much of the time because of my grandchildren in the day so I make use of the time before they wake up and go to school. So I think, basically that stopped me from participating in activities during the day is partly because of them. However, in the evening, I have to be with my husband so the day is just gone like that. (...)

Interviewee 2: Family commitments. Because I do not have a helper too, I have two kids. I have to cook for my husband because he packs food every day. Then I also juggle between my (teaching) tuition.

While Interviewee 1 comments on how she spends her time to manage the needs of her grandchildren, evidently, she admits that this stops her from engaging in any form of physical activity. Interviewee 2 has established that family commitments are the main barrier of her not exercising. As a housewife, she takes care the needs of her family and provides additional income for the family by offering tuition services. All participants mentioned that they experience time limitation due to family commitments that prevents them from participating physical activity. The providence of family support is the most important for all three participants. Participants believe that they are able to find a sense of identity, achievement, productivity and satisfaction within attaining the needs of the family.

\section{Minimal promotion of subsidized initiatives}

Initiatives were rolled out to promote healthy living and physical activity is one of the main categories of it. However, the citizen's lack of awareness of these initiatives does not fully utilize the full benefits of it. When I asked interviewee 1 on her knowledge towards one of the more popular initiative set off my Sport Singa- pore:

Interviewee 1: (...) I am not aware of that (ActiveSG SGD\$100). I have heard of the SG50 but I have not heard about this.

From the interview with Interviewee 1, she was not aware of the ActiveSG SGD $\$ 100$ credits that she is entitled. An opportunity to encourage exercising may have been missed for Interviewee 1 due to the lack of publicity. Most initiatives are not or minimally advertised. These initiatives are usually brought to knowledge by word-of-mouth from friends or self-research.

Interviewer: Have you participated in government-encouraged exercises such as taking classes from ActiveSG? If yes, would you be able to describe the experience?

Interviewee 3: never join (government-encouraged exercises) before. I go those ones below my house or the park/garden where many aunties meet up and exercise together.

Lack of awareness was also present in interviewee 3's interview. Minimal exposure towards any initiatives of the Healthy Living Master plan was to her knowledge. Interviewee 3 reflected that she knows that there are exercise groups that are conducting near her vicinity but she was not motivated to find out more about it.

Interviewer: Have you participated in government-encouraged exercises such as taking classes from ActiveSG?

Interviewee 2: Yes, I did one set of zumba and one set of yoga.

Interviewer: so you are aware of the $\$ 100$ credits given by the government.

Interviewee 2: yes.

Interviewer: So did you utilize everything?

Interviewee 2: No.

Interviewer: Do you have any health issue that you believe prevents you from exercising?

Interviewee 2: Before the (my) operation I was okay. I do not have any major illness at all. Before my wedding, I used to exercise regularly, like I used to go to the stadium and jog for like 10 rounds.

Interviewee 2 reflected that she was aware of the credits but did not fully utilize it. Participation in Zumba and yoga was encouraged by the credits but due to some health issue, she decided to drop it. Interviewee 2 used to be physically active but as soon as she got married and held on to the responsibility of taking care of the family, her priorities shifted. In interviewee 2's case, it shows that the knowledge of the credits did encourage her to participate in physical activity. Hence, if government initiatives are advertised and more people get to know, people would be willing to try 


\section{Discrimination through usage of language}

Although most respondents mentioned that race do not affect their motivation to exercise, subtle discrimination was noticed. Interestingly, the expression of discrimination came from our Indian respondent, which is the minority ethnic in Singapore.

Interviewee 2: At certain exercises, I find that mostly (most participants) are Chinese and the instructors explains using Chinese.: I tried (to raise the issue to her). Therefore, she tried to speak in English but eventually switch back to Chinese.

Interviewee 2 faced a minor discrimination while attending exercise classes that affected her ability to follow in classes. While she tried to resolve this problem that she faced by raising up the issue, it did not work. The instructor's used of language was not intentional, however Interviewee 2 still did feel indifferent to the community and prevented her from developing a sense of identity in the community.

Interviewee 1: I do not see any discrimination, when you use the term discrimination. But is just that laziness (...)

Interviewee 2: Sports (has) no boundaries and discrimination. Everybody have fun exercising with each other.

However, the other respondent did not feel and would not inflict any sort of discrimination. Sports encourage people to come together and bond and discrimination should not be tolerated.

\section{DISCUSSION}

This study aims to identify the barriers towards exercise and physical activity of different ethnic groups in middle-aged Singaporeans and it provides an account of the lived struggled experiences faced by them. The emphasis is placed upon different ethnic groups consisting of Chinese, Malay, and Indians. This is particularly important as Singapore place much emphasis on equality among races. The findings of this paper illuminate the barriers toward sports in Singaporean women that needs to be addressed due to the increased in obesity rate. This study has revealed the top three barriers towards sports and they are priority of commitments, minimal promotion of subsidized initiatives by the government and language discrimination. To develop clear strategies to encourage exercising, the government, national health organizations and the people needs to work together.

\section{Incorporating physical activity as part of routine}

Family and work commitments are the similar reason that dis- courages respondents to not exercise. Tending to the family and attending to the needs of every individual member can be a challenging yet fulfilling task. The act of balance between the engagement of physical activity to keep a healthy lifestyle and family commitment has to be established. The importance of these areas are not be neglected. In order to prevent weight gain and obesity, the recommended physical activity engagement is 150 to 250 min of moderate intensity of aerobic activity per week (Health Promotion Board, 2011). BMI is commonly used in Asian countries to tabulate population data and formulate prevention programmes (WHO Expert Consultation, 2004). With a BMI more than $25 \mathrm{~kg} / \mathrm{m}^{2}$, it is considered overweight. However, one can reduce with an increased in physical activity and a reduction in calorie intake.

Resultant of family and work commitments is having limited time to exercise. With an average of more than $11 \mathrm{hr}$ spent on sedentary activity, sedentary behaviours are prominent leading to obesity (Müller-Riemenschneider et al., 2016). However, one can take in account and prioritize accordingly to achieve a balance. Education to the public-by-public healthcare organizations should be made and emphasized more frequently. Booths can be setup in more prominent area such as malls. Such initiatives are important because if the perception of the public is more important in generating interests in finding more way to be physically active. So, instead of rolling out countless initiatives and waiting for people to participate, the wants in people can be generated.

\section{Intensive promotion of sports programmes}

Lack of awareness of subsidized initiatives to the public is an area for exploration. The full effect of the programmes should be made known to the public in order for the public to utilize the benefits. The most fundamental concept of marketing is marketing mix whereby a company uses to generate a chain of responses in the targeted market. Promotion is one of the 4Ps in the marketing mix (Khan, 2014). The importance of promotion of programmes information to generate awareness and interest to the public can be held in line with the goals of marketing mix.

Apart from the respective websites and word of mouth, aggressive promotions interventions can be implemented in traditional media, face-to-face and social media to create awareness and each having a unique set targeted audience. Traditional media through the use of radios, televisions and website can also be used to target audience that are less tech-savvy. Health promotions programmes can also be advertise through face-to-face and are more likely to have a better result through personal interaction and mutual un- 
derstanding. Personalize information can be conveyed and be accordingly structured to the needs of the targeted group.

With the reliance on technology, entertainments are sought after through many avenues and social media is one of them. More common social media platforms includes Facebook, Instagram and twitter. Social media promotional strategies are able to promote an in between of communication and interpersonal engagement through online which allows information to be delivered to a large capacity of targeted audience (An et al., 2017). Health organization could advertise the existence and merits of the programmes to achieve better awareness and better turnouts. The combination of the three areas of promotion enables the knowledge of the programme to reach out the targeted audiences and encouraging them to participate.

\section{Use of language in exercise classes}

The multiracial coexistence in Singapore makes our country a unique and attractive place to stay. As a tourism hub, it is one of Singapore's key service sectors and economic pillars (Singapore Tourism Board, 2017). Tourism is one of the key reason contributing to the thrive of economy in Singapore. People from all over the world migrate to Singapore, as discrimination seems to barely exist. Over $70 \%$ of Singaporeans are Chinese and the rest are Malays and Indians (Prime Minister's Office, 2108). With the vast majority of instructors being Chinese, it is inevitable that they would progressively go into teaching in a language that they would most prefer. Hence, to ensure that the minority Indians and Malays do not feel neglected, the use of English throughout the session should be enforced regardless majority ethnic of the participants.

The findings of this paper reveal that incorporating sports as part of routine, aggressive promotion of exercise programmes to gain awareness and the appropriate use of language in exercise classes would be able to encourage female Singaporeans to exercise. This study set exploration the discussion in the barriers towards the lack of physical activity engagement among Singaporeans women and the information would be helpful in setting up future initiatives. That being said, the use of language can be standardized in teaching to provide a more comfortable environment in exercise classes. The result can give a detailed account of the lived struggles of middle aged female Singaporeans of ethnic groups. The understanding of the barriers faced can promote the achievement of vision 2030 of living better through sports as set forth by the government. With an understanding of attainment of a healthy lifestyle, the result of this study may contribute in the further understanding in the barriers towards the lack of exercise between different ethnic groups of female Singaporeans. This study may contribute in the formations of motivations to exercise in further studies.

\section{CONFLICT OF INTEREST}

No potential conflict of interest relevant to this article was reported.

\section{REFERENCES}

An R, Ji M, Zhang S. Effectiveness of social media-based interventions on weight-related behaviors and body weight status: review and metaanalysis. Am J Health Behav 2017;41:670-682.

Ball K, Schoenaker DAJM, Mishra GD. Does psychosocial stress explain socioeconomic inequities in 9-year weight gain among young women? Obesity (Silver Spring) 2017;25:1109-1114.

Blake H, Stanulewicz N, Mcgill F. Predictors of physical activity and barriers to exercise in nursing and medical students. J Adv Nurs 2017;73: 917-929.

Dale GA. Existential phenomenology: emphasizing the experience of the athlete in sport psychology research. Sport Psychol 1996;10:307-321.

Green J, Thorogood N. Qualitative methods for health research. London: Sage; 2018.

Health Promotion Board. National physical activity guidelines: Summary guide for professionals [Internet]. Singapore: Health Promotion Board; 2011 Jul [cited 2018 Aug 1]. Available from: https://www.healthhub. sg/sites/assets/Assets/PDFs/HPB/PhysicalActivityPDFs/NPAG_Summary_Guide.pdf.

Health Promotion Board. Obesity. HPB-MOH clinical practice guidelines [Internet]. Singapore: Health Promotion Board; 2016 Jun [cited 2018 Mar 17]. Available from: https://www.hpb.gov.sg/docs/default-source/ pdf/obesity-cpg_main_for-online-30-aug.pdf?sfvrsn=2288eb72_0.

Health Promotion Board. Physical activity programmes [Internet]. Singapore: Health Promotion Board; c2017 [cited 2017 Feb 27]. Available from: https://www.hpb.gov.sg/healthy-living/physical-activity/physical-activity-programmes.

Holloway I, Galvin K. Qualitative research in nursing and healthcare. Chichester (UK): Wiley Blackwell; 2017.

Justine M, Azizan A, Hassan V, Salleh Z, Manaf H. Barriers to participation in physical activity and exercise among middle-aged and elderly individuals. Singapore Med J 2013;54:581-586.

Khan MT. The concept of marketing mix and its elements: a conceptual review paper. Int J Info Bus Manag 2014;6:95-107. 
Lee BA, Oh DJ. Effect of regular swimming exercise on the physical composition, strength, and blood lipid of middle-aged women. J Exerc Rehabil 2015;11:266-271.

Malhotra R, Malhotra C, Chan A, Østbye T. Life-course socioeconomic status and obesity among older Singaporean Chinese men and women. J Gerontol B Psychol Sci Soc Sci 2013;68:117-127.

Malterud K. Qualitative research: standards, challenges, and guidelines. Lancet 2001;358:483-488.

Moon DC, Kim MJ, Lee CM. Meta-analysis on the effect of combined exercise program intervention on Korean middle-aged women. J Exerc Rehabil 2018;14:394-398.

Moustakas K. Phenomenological research methods. Thousand Oaks (CA): Sage; 1994.

Müller-Riemenschneider F, Ng SH, Koh D, Chu AH. Objectively measured patterns of activities of different intensity categories and steps taken among working adults in a multi-ethnic Asian population. J Occup Environ Med 2016;58:e206-211.

Nguyen-Michel ST, Unger JB, Hamilton J, Spruijt-Metz D. Associations between physical activity and perceived stress/hassles in college students. Stress Health 2006;22:179-188.

Norris R, Carroll D, Cochrane R. The effects of physical activity and exercise training on psychological stress and well-being in an adolescent population. J Psychosom Res 1992;36:55-65.

Prime Minister's Office. Population trends [Internet]. Singapore: Prime Minister's Office; c2018 [cited 2018 Mar 31]. Available from: https:// www.population.sg/population-trends/people-society.

Rossi FE, Lecca AR, Martins LGP, Takahashi LSO, Christofaro DGD,
Gobbo LA, Freitas IF Jr. Physical exercise programs at Basic Healthcare Units decrease body fat and improve the functional capacity of women over 50 years old. J Exerc Rehabil 2017;13:315-321.

Scharff DP, Homan S, Kreuter M, Brennan L. Factors associated with physical activity in women across the life span: implications for program development. Women Health 1999;29:115-134.

Singapore Tourism Board. About ATB [Internet]. Singapore: Singapore Tourism Board; c2017 [cited 2018 Mar 31]. Available from: https:// www.stb.gov.sg/about-stb.

Sport Singapore. Active SG [Internet]. Singapore: Sport Singapore; c2017 [cited 2018 Mar 19]. Available from https://www.myactivesg.com.

Sport Singapore. Vision 2030: live better through sports [Internet]. Singapore: Sport Singapore; c2015 [cited 2018 Aug 1]. Available from: https://www.sportsingapore.gov.sg/ /media/corporate/files/about/annual\%20reports/sport\%20singapore\%20fy2014\%20annual\%20report. pdf.

Stewart B, Smith A, Moroney B. Capital building through gym work. Leisure Stud 2013;32:542-560.

Suter K. The importance of sport in society. Australia: Global Directions; c2009 [2018 Mar 13]. Available from: http://www.global-directions. com/Articles/Business/EconomicImpactOfSport.pdf.

Waters CN, Ling EP, Chu AH, Ng SH, Chia A, Lim YW, et al. Assessing and understanding sedentary behaviour in office-based working adults: a mixed-method approach. BMC Public Health 2016;16:360.

WHO Expert Consultation. Appropriate body-mass index for Asian populations and its implications for policy and intervention strategies. Lancet 2004;363:157-163. 